\section{(6) OPEN ACCESS}

\begin{abstract}
- Additional material is published online only. To view please visit the journal online (http://dx.doi.org/10.1136/ bjophthalmol-2016-309376).

${ }^{1}$ UCL Institute of Ophthalmology, University College London, London, UK ${ }^{2}$ Moorfields Eye Hospital, London, UK

${ }^{3}$ Westmead Institute for Medical Research, Westmead, University of Sydney, Sydney, New South Wales, Australia
\end{abstract}

\section{Correspondence to}

Michel Michaelides, UCL Institute of Ophthalmology, 11-43 Bath Street, London EC1V 9EL, UK; michel. michaelides@ucl.ac.uk

Received 22 July 2016 Revised 31 October 2016 Accepted 9 November 2016

\section{CrossMark}

To cite: Strong $S$, Liew G, Michaelides M. Br J

Ophthalmol 2017;101:3137.

\title{
Retinitis pigmentosa-associated cystoid macular oedema: pathogenesis and avenues of intervention
}

\author{
S Strong, ${ }^{1,2} \mathrm{G} \mathrm{Liew}^{3}$ M Michaelides ${ }^{1,2}$
}

\section{ABSTRACT}

Hereditary retinal diseases are now the leading cause of blindness certification in the working age population (age 16-64 years) in England and Wales, of which retinitis pigmentosa (RP) is the most common disorder. RP may be complicated by cystoid macular oedema (CMO), causing a reduction of central vision. The underlying pathogenesis of RP-associated CMO (RPCMO) remains uncertain, however, several mechanisms have been proposed, including: (1) breakdown of the blood-retinal barrier, (2) failure (or dysfunction) of the pumping mechanism in the retinal pigment epithelial, (3) Müller cell oedema and dysfunction, (4) antiretinal antibodies and (5) vitreous traction. There are limited data on efficacy of treatments for RP-CMO. Treatments attempted to date include oral and topical carbonic anhydrase inhibitors, oral, topical, intravitreal and periocular steroids, topical non-steroidal antiinflammatory medications, photocoagulation, vitrectomy with internal limiting membrane peel, oral lutein and intravitreal antivascular endothelial growth factor injections. This review summarises the evidence supporting these treatment modalities. Successful management of RP-CMO should aim to improve both quality and quantity of vision in the short term and may also slow central vision loss over time.

\section{INTRODUCTION}

Cystoid macular oedema (CMO) may complicate retinitis pigmentosa (RP) and has been reported to occur in $10 \%-50 \%$ of patients. ${ }^{1-4}$

Hereditary retinal diseases are now the leading cause of blindness certification in the working age population (age 16-64 years) in England and Wales, of which RP is the most common disorder. ${ }^{5}$ RP causes nyctalopia and progressive peripheral visual field loss, with particular disability experienced when disease progression results in central visual compromise. One important treatable cause of central vision loss is RP-associated CMO (RP-CMO). ${ }^{6}$ Improved understanding of the underlying mechanisms and response to treatments of RP-CMO is required to facilitate better-targeted and more efficacious therapies. In this review, we will discuss the pathogenesis of RP-CMO and the multiple avenues of intervention that have been investigated or being considered.

\section{PATHOGENESIS}

No single aetiology has been definitively established to cause RP-CMO. While we describe several individually proposed mechanisms, it is plausible that RP-CMO may result from a combination of these.

\section{Breakdown of the blood-retinal barrier}

The blood-retinal barrier (BRB) exists to maintain homeostasis via the highly selective diffusion and active transport of molecules into and out of the retina, thus preventing extravascular accumulation of fluid within the retina. ${ }^{7}$ This is achieved in two ways: (i) an outer barrier of apical tight junctions between retinal pigment epithelial (RPE) cells ${ }^{8} 9$ and (ii) an inner barrier of tight junctions between vascular endothelial cells. ${ }^{10} \mathrm{CMO}$ can occur from BRB breakdown secondary to RPE and/or endothelial damage/dysfunction.

Studies have investigated whether one barrier is more affected than the other in order to better focus on potential therapies. Vinores $e t$ al ${ }^{11}$ used immunolocalisation of endogenous albumin to highlight areas of extravasation in normal eyes compared with those with RP. In eyes with RP alone, albumin leakage was greatest from the inner barrier. ${ }^{11}$ In RP-associated with other ocular complications (eg, aphakia, glaucoma), leakage varied between the inner and outer barriers. No correlation was found between severity of photoreceptor degeneration and albumin leakage, ${ }^{11}$ suggesting that therapies for RP-CMO could be used regardless of underlying disease status.

The release of 'toxic products' from degenerating retina/RPE may cause RP-CMO by disrupting the BRB. ${ }^{12}$ In keeping with CMO observed in other disorders, RP-CMO has been associated with release of vascular endothelial growth factor (VEGF), adenosine, ${ }^{7}$ prostaglandins,${ }^{13}$ histamine, ${ }^{14}$ insulin-like growth factor $1,{ }^{15}$ tumour necrosis factor $\alpha$ and interleukin- $1 \alpha$ and interleukin- $1 \beta .{ }^{16}$

\section{Failure (or dysfunction) of the pumping mechanism in the RPE}

An important function of the RPE is to pump fluid out from the subretinal space in order to maintain the negative hydrostatic pressure required for adhesion between RPE and photoreceptors. ${ }^{17}$ Under normal conditions, $\mathrm{Cl}^{-}$enters the RPE cell via $\mathrm{Na}^{+}$/ $\mathrm{K}^{+}$ATPase located on the apical membrane and exits via $\mathrm{Cl}^{-}$channels on the basolateral membrane. It is this active transport that drives water through aquaporin channels from the subretinal space into the choriocapillaris. Failure (or dysfunction) of this pumping mechanism may occur in RP, thus resulting in CMO. The presence of CMO has been suggested to result in loss of polarised distribution of membrane-bound carbonic anhydrase (CA) IV in the $\mathrm{RPE}$, further contributing to RP-CMO. ${ }^{10}$

\section{Müller cell oedema and dysfunction}

The Müller cell is essential for visual transduction and retinal homeostasis, including fluid dynamics. 
Water enters the retina by two routes: directly from the blood, coupled with glucose uptake and/or as a by-product of aerobic metabolism; with the bidirectional movement of water osmotically coupled with the transport of osmolytes such as potassium. $^{18}$

Potassium ions are released by activated retinal neurons. To prevent a build-up and potential excitotoxicity, potassium is passively taken up into Müller cells via inwardly rectifying channels (Kir2.1) with release of potassium occurring via Kir4.1 channels. ${ }^{18}$ Kir channels consist of two transmembrane regions with cytosolic $\mathrm{NH}_{2}$ and $\mathrm{COOH}$ termini connected by a pore-forming loop. Molecules such as $\mathrm{Mg}^{2+}$ and polyamines are able to physically block this channel pore from allowing outward movement of $\mathrm{K}^{+}$, while still able to accept inward movement of $\mathrm{K}^{+19}$ Under pathological conditions such as inflammation and oxidative stress, Kir4.1 channels redistribute, becoming more evenly spread throughout the Müller cell. However, Kir2.1 channels do not redistribute, resulting in intracellular potassium overload, increased osmotic pressure within the Müller cell, reduction in water efflux and ultimate Müller cell swelling. ${ }^{18}$

Makiyama et al used optical coherence tomography (OCT) to investigate the prevalence and spatial distribution of cystoid spaces (CS) in patients with RP. Seventy-four of 275 patients $(27 \%)$ demonstrated RP-CMO in at least one eye. Inner nuclear layer (INL) CS were observed in 99\% of eyes with CMO. The outer nuclear layer (ONL)/outer plexiform layer was involved in $28 \%$ and ganglion cell layer involved in $7 \% .^{20}$ Müller cell bodies reside in the INL, which supports the hypothesis of Müller cell swelling and dysfunction. Interestingly, 79\% of CS were located in areas of relatively well-preserved outer retina; ${ }^{20}$ in keeping with the observation that CMO is seen more commonly in less advanced RP compared with late-stage RP.

\section{Antiretinal antibodies}

Serum levels of IgG, IgA and IgM have been investigated in 52 patients with RP compared with 40 controls. Higher levels of IgM were found in patients with RP compared with controls. ${ }^{21}$ Spiro et $a{ }^{22}$ however, found no difference in IgM levels between 75 patients with RP and 51 controls. Spalton et al performed immunological studies on 17 patients with RP with central and/or peripheral vascular leakage observed on fluorescein angiogram (FA). Five out of 17 patients had raised IgM unrelated to degree of vascular leakage. All patients demonstrated positive immunofluorescence to rat photoreceptors at 1:5 dilution of serum, however, this could be attributed to cross-reactivity of smooth muscle antibodies with photoreceptor contractile organelles. $^{12}$

Antiretinal antibodies have been prospectively studied in 30 patients with RP-CMO and 30 patients with RP without CMO. Antiretinal antibodies were found in 27 of 30 patients with RP-CMO compared with 4 of 30 patients with RP without $\mathrm{CMO}^{23}$ Nevertheless, the role of antiretinal antibodies in RP progression or RP-CMO remains unclear, with many unanswered questions including whether they are a secondary consequence of the degenerative process, the wide range of autoantibodies identified and the high prevalence in normal controls. $^{2324}$

\section{Vitreous traction}

It has been suggested that vitreous traction and epiretinal membrane contributes to RP-CMO by causing mechanical damage to Müller cells, an inflammatory reaction with subsequent capillary dilatation and leakage. ${ }^{25} 26$ Schepens et $a l^{26}$ and Takezawa et $a l^{27}$ have reported cases of RP-CMO in the presence of vitreous traction.

\section{DIAGNOSIS AND MONITORING OF RP-CMO}

Prior to the advent of OCT, monitoring RP-CMO included slit-lamp biomicroscopy together with FA. OCT has since been shown to be more sensitive in detecting macular oedema compared with biomicroscopy in patients with diabetic retinopathy and RP-CMO. ${ }^{28} 29$ OCT can detect CS in RP-CMO even when little, or no leakage is demonstrated on $\mathrm{FA}^{29}{ }^{30}$ and being noninvasive is ideal for monitoring RP-CMO. No studies have yet been performed using OCT-Angiography to investigate RP-CMO.

RP-CMO is not always associated with a reduction in visual acuity (VA). ${ }^{31}$ Oishi et $a l^{32}$ found no correlation between total macular thickness and VA. The integrity of the inner segment ellipsoid layer, however, has been shown to correlate well with VA and inform the likely prognosis. ${ }^{31-33}$ Central vision loss in RP-CMO may be due to retinal thinning (from atrophy), thickening (from CMO) or a combination of both. ${ }^{34}$ Anatomical but not functional improvement following treatment could be due to underlying retinal dysfunction/loss.

Automated static perimetry may also be useful for monitoring $\mathrm{RP}-\mathrm{CMO}$ given the documented correlation between changes in retinal thickness due to $\mathrm{CMO}$ and retinal sensitivity. ${ }^{35-37}$

\section{INHERITANCE PATTERNS AND SPECIFIC ASSOCIATIONS}

While pedigree structures may be informative, definitive conclusions on mode of inheritance can only be made with a molecular diagnosis.

In a retrospective cohort study, CMO was present in 133/581 (23\%) Italian patients with RP. This appeared to be significantly associated with autosomal dominant (AD) inheritance. ${ }^{2}$ In contrast, Liew et $a l^{38}$ constructed pedigrees for patients with RP-CMO in a retrospective cohort and found 55/81 (68\%) patients with autosomal recessive (AR) inheritance (4 of whom were molecularly proven).

A family with AD-RP associated with the p.P347L variant in rhodopsin (RHO) has been reported, where all four children had bilateral CMO, suggesting this RHO mutation may be associated with early onset CMO. ${ }^{39}$

RP-CMO has been associated with female gender ${ }^{2}$ and does not appear to be age-related. ${ }^{1}$

\section{AVENUES OF INTERVENTION}

Despite RP being the most common inherited retinal degeneration in the working age population, it remains a rare condition with only a proportion of these patients developing CMO. ${ }^{5}$ Therefore, it is challenging to set up clinical trials targeting RP-CMO, with most evidence to date comprising case reports/ series and relatively small prospective/retrospective studies.

We conducted a PubMed search to include all reports/studies of interventional treatment for RP-CMO published between 1975 and 2016. The search strategy involved the terms 'RP', 'rod cone dystrophy', 'retinal dystrophy', 'inherited retinal dystrophy' and 'macular oedema'. We identified 203 publications, the abstracts of which were retrieved and reviewed. Inclusion criteria included prospective and retrospective reports/studies using a drug and/or procedure to treat RP-CMO. We also included patients with syndromic RP such as Usher syndrome and those with Coats-like exudation. We excluded patients with membrane-type frizzledrelated protein (MFRP)-related nanophthalmos-retinitis pigmentosa-foveoschisis-optic disc drusen syndrome due to its complexity 
and rarity. We identified 46 reports/studies that met our inclusion criteria and retrieved these articles.

The majority of published evidence was in the form of small cohort and case-control studies. These may be influenced by publication bias, as negative reports are less likely to be published. There are no large randomised control trials (RCTs) to date. We did not construct funnel plots or perform other statistical tests for publication bias due to the small number of studies and the highly heterogeneous populations and study designs.

Significant studies that describe interventions in detail or highlight important/interesting points are mentioned in the text. Online supplementary table S1 provides an overview of all studies that met our inclusion criteria.

\section{Pharmacological}

\section{CA inhibitors: oral and topical}

Inhibition of CA IV results in acidification of the subretinal space, increased chloride ion transport, with subsequent movement of water across the RPE into the choroid. ${ }^{10}$

Several studies have shown RP-CMO improvement following treatment with CA inhibitors (CAIs). ${ }^{38}{ }^{40-53}$ In the largest retrospective study to date involving 81 patients (157 eyes) with RP-CMO, objective improvement on OCT was observed in 53\% of patients (40\% of eyes) using topical dorzolamide and in $41 \%$ of patients ( $28 \%$ of eyes) using oral acetazolamide ${ }^{38}$ (figure 1 ). VA improved from $6 / 15$ to $6 / 12$ in most patients. AR-RP and greater initial central macular thickness (CMT) predicted better response to treatment.

In another retrospective study, 33 eyes $(51 \%)$ of 20 patients with RP-CMO using topical dorzolamide demonstrated CMT reduction of at least $11 \% .{ }^{46}$ While there are other reports in keeping with these findings, ${ }^{42}$ some studies have documented improvement of anatomy or leakage on FA only, with little or no corresponding improvement in VA. ${ }^{47-49}$

In a prospective, crossover study, 9 out of 17 patients using oral methazolamide demonstrated angiographic improvement of $\mathrm{CMO}$, however, VA improved in at least one eye, by at least 2 lines in only 3 patients. ${ }^{43}$ Another prospective, masked, crossover study using oral acetazolamide versus placebo observed VA improvement of at least one line, in at least one eye in 10 out of 12 patients. Three of these patients initiated on placebo only demonstrated improvement once switched to acetazolamide. ${ }^{44}$

Location of CS in RP-CMO may influence response to treatment with CAIs. Acetazolamide cannot readily enter the neurosensory retina making it potentially less effective at reducing INL CS. ${ }^{54}$ However, with good access to the RPE basolateral membrane, ${ }^{41}$ acetazolamide may be more effective at reducing ONL CS. ${ }^{55}$

Rebound CMO has been observed after stopping CAIs. ${ }^{42} 47$ Importantly, a restored response has been demonstrated after the re-introduction of CAI treatment following a period of discontinued usage (between 1 and 6 months) in three patients with rebound RP-CMO. ${ }^{53}$

Oral CAIs have more side effects than topical CAIs ranging from fatigue, loss of appetite and limb paraesthesia to the development of kidney stones, aplastic anaemia and electrolyte disturbance including hypokalaemia with potential associated cardiac arrhythmia. ${ }^{55}$

Steroids: oral, periocular and intravitreal

Steroids reduce the synthesis and release of pro-inflammatory cytokines, including: prostaglandins, leukotrienes, VEGF and

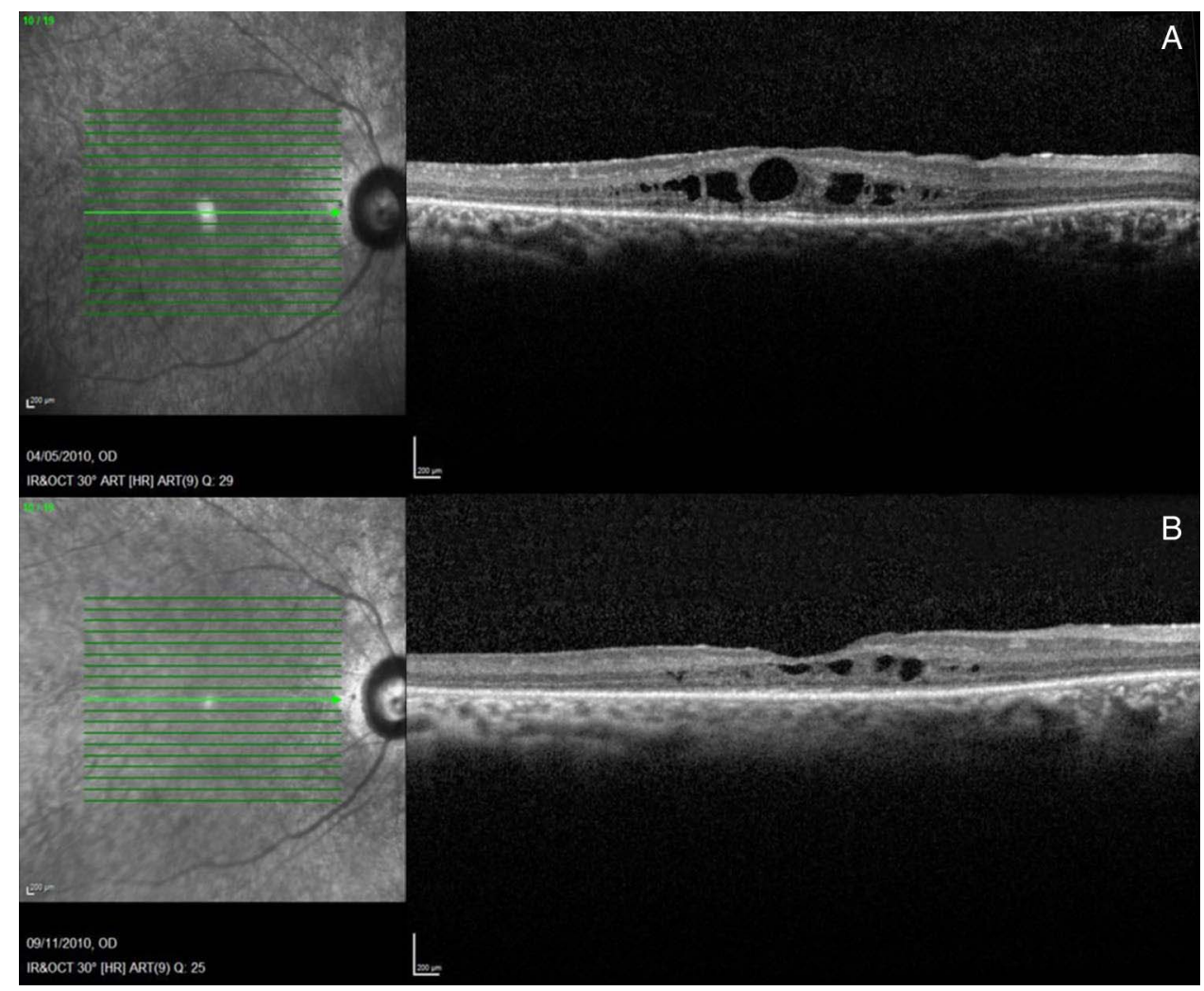

Figure 1 Spectral domain optical coherence tomography of a man aged 30 years with autosomal recessive retinitis pigmentosa and cystoid macular oedema. (A) Before treatment was initiated (visual acuity (VA) 6/18). (B) Following 6 months usage of topical carbonic anhydrase inhibitors (VA 6/12). 
intercellular adhesion molecule $1 .^{56-59}$ This, together with suppression of inflammatory cell proliferation and migration contributes to improved BRB function and reduction of CMO. Steroids have been observed to improve VA and/or CMT in RP-CMO. ${ }^{4}$ 60-74

A 1-year pilot study using oral deflazacort in 10 patients with RP-CMO reported significant improvements in near VA, retinal sensitivity and angiographic findings. ${ }^{64}$ No ocular or systemic side effects were recorded.

Five patients with RP-CMO underwent unilateral intravitreal injection of $4 \mathrm{mg}(0.1 \mathrm{~mL})$ of triamcinolone acetonide (IVTA). CMT improved from $418 \mu \mathrm{m}$ (range, 376-626 $\mu \mathrm{m}$ ) at baseline to $224 \mu \mathrm{m}$ (range, 214-326 $\mu \mathrm{m}$ ) at 1 month, $275 \mu \mathrm{m}$ (range, $215-584 \mu \mathrm{m})$ at 3 months and $312 \mu \mathrm{m}$ (range, 239-521 $\mu \mathrm{m}$ ) at 6 months. VA improved in two patients by 1 month but was not maintained. CMO recurrence occurred in two patients between 3 and 6 months. ${ }^{4}$

In comparison, a prospective, non-randomised trial compared 20 eyes of 20 patients with RP-CMO treated with IVTA with 20 eyes of 20 patients with RP-CMO who declined treatment. All treated patients showed anatomical improvement, greatest at 3 months postinjection. No statistical improvement in VA was observed. At day 1 post-IVTA, 10 eyes (50\%) had a raised intraocular pressure (IOP) $(>21 \mathrm{~mm} \mathrm{Hg})$ including 2 patients (10\%) measuring between 30 and $35 \mathrm{~mm} \mathrm{Hg}$. All IOPs returned to baseline within 6 months. ${ }^{6}$

A case report of bilateral RP-CMO refractory to IVTA reported CMO reduction and VA improvement following bilateral sub-Tenon injections of triamcinolone. ${ }^{62} \mathrm{CMO}$ recurred in one eye at 3 months.

Intravitreal dexamethasone implant (Ozurdex, Allergan, Irvine, California, USA) has also been used in three patients with RP-CMO refractory to oral CAIs and/or sub-Tenon triamcinolone and/or topical non-steroidal anti-inflammatory (NSAID). Two patients required retreatment at 3 months due to recurrence. $^{72}$ Another case report demonstrated similar outcomes with initial improvement of CMO and VA, but recurrence at 23 months. $^{68}$

The use of regular steroids in RP-CMO is significantly limited by their side-effect profile. Ozurdex appears to have a lower incidence of cataract and raised IOP compared with IVTA in treatment of retinal vein occlusion-CMO, ${ }^{75}{ }^{76}$ however, the incidence in RP-CMO is unknown.

\section{Combination of topical NSAID together with topical steroid or topical CAI}

A case report using topical steroid (prednisolone acetate 1\%) together with topical NSAID (ketorolac trometamol $0.5 \%$ ) in a woman aged 85 years with unilateral RP-CMO demonstrated $\mathrm{CMO}$ resolution and VA improvement at 3 months. $\mathrm{CMO}$ recurrence on cessation required retreatment to good effect. ${ }^{77}$

A recent prospective study of 18 patients randomised 15 eyes to topical ketorolac and 13 eyes to topical dorzolamide for 12 months. No significant change in CMT was observed in either group. VA improved in both groups at 6 months, however, this improvement was lost in the dorzolamide group at 12 months. $^{78}$

\section{Intravitreal anti-VEGF}

The VEGF family includes VEGF-A, VEGF-B, VEGF-C, VEGF-D and placental growth factor. ${ }^{79}$ In addition to promoting angiogenesis, VEGF-A reduces endothelial barrier function and increases permeability of choroidal vessels, both of which cause $^{\mathrm{CMO}}{ }^{79}$
Salom et al identified markedly lower levels of VEGF-A in the aqueous humour of 16 eyes of 16 patients with RP $(94.9 \pm 99.8$ (mean $\pm \mathrm{SD}$ ) $\mathrm{pg} / \mathrm{mL}$ ) compared with the same number of controls $(336.5 \pm 116.8 \mathrm{pg} / \mathrm{mL})$. Relative hyperoxia of the inner retina due to photoreceptor cell death may reduce VEGF production from retinal cells such as pericytes, endothelial cells, glial cells, Müller cells and ganglion cells. ${ }^{80}$

While no studies have assessed vitreous levels of VEGF in patients with RP or RP-CMO, anatomical and/or functional improvement of RP-CMO has been observed following intravitreal anti-VEGF medication. ${ }^{81-86}$ Anti-VEGF agents are routinely used to treat $\mathrm{CMO}$ and neovascularisation $(\mathrm{NV})$ in multiple retinal diseases. $\mathrm{NV}$ is rare in $\mathrm{RP}$; Triolo et $a l^{87}$ reported choroidal NV in 3 of 176 eyes (2\%) with RP. Indeed, intravitreal bevacizumab (Avastin, Genentech/Roche, South San Francisco, California, USA) has been observed to improve RP-choroidal NV. ${ }^{88}{ }^{89}$ While VEGF may contribute to RP-CMO formation, anti-VEGF medication remains under active study as a treatment modality.

\section{Pegaptanib}

A case report using a single intravitreal injection of $0.3 \mathrm{mg}$ pegaptanib (Macugen, Eyetech Pharmaceuticals and Pfizer, New York, New York, USA) together with oral acetazolamide in a man aged 33 years with RP-CMO demonstrated improvement of CMT and VA, which was maintained at 4 months. ${ }^{81}$

\section{Bevacizumab}

Bevacizumab has been used off-label to treat RP-CMO with varying results. Melo et al observed neither anatomical nor functional improvement in two eyes of two patients following treatment with a single injection of intravitreal $1.25 \mathrm{mg}$ bevacizumab: case 1 maintained VA of 20/200 both prebevacizumab and postbevacizumab injection with no further improvement following IVTA. Case 2 had a baseline VA of 20/100, which worsened at 1 month postbevacizumab to 20/200. Due to worsening cataract, the patient subsequently underwent phacoemulsification plus IVTA and VA at 3 months postoperation improved to $20 / 25 .^{90}$ In contrast, Yuzbasioglu et al performed an average of 3.3 (range, 1-8) injections of $1.25 \mathrm{mg}$ bevacizumab over 10.3 (range, 6-14) months in 13 eyes of 7 patients and observed a reduction of CMT from $370.15 \mu \mathrm{m}$ (range, 245-603 $\mu \mathrm{m})$ at baseline to $142.53 \mu \mathrm{m}$ (range, $124-168 \mu \mathrm{m}$ ). Pretreatment and post-treatment VA ranged from 5/400-20/100 to $20 / 200-20 / 63$, respectively. ${ }^{82}$

\section{Ranibizumab}

Artunay et al enrolled 30 eyes of 30 patients with RP-CMO into a prospective, controlled interventional study of $0.5 \mathrm{mg}$ intravitreal ranibizumab (Lucentis; Genentech). Thirteen eyes (87\%) in the treatment group demonstrated a significant reduction of $\mathrm{CMO}$ at 6 months. No statistically significant difference in VA was seen between the groups. ${ }^{83}$

\section{Aflibercept}

Improvement of CMT and VA following a single unilateral intravitreal injection of aflibercept (Eylea; Regeneron Pharmaceuticals, Tarrytown, New York, USA and Bayer Healthcare Pharmaceuticals, Berlin, Germany) in a patient aged 52 years with RP-CMO was observed and maintained at 6 months. ${ }^{84}$ We have observed similar responses ${ }^{85}$ and have commenced a prospective study to determine safety and efficacy of intravitreal aflibercept in RP-CMO (ClinicalTrials.gov identifier NCT02661711). Aflibercept may be superior to other 
anti-VEGF medications due to its intermediate size $(115 \mathrm{kDa})$ and higher binding affinity.

\section{Nutritional}

Oral lutein

Lutein and zeaxanthin are carotenoid pigments that contribute to the formation of macular pigment, which is thought to be protective against oxidative damage. ${ }^{91}$ A 48 -week study tested the effect of oral lutein on CMT in 39 patients with RP. Lutein was found to have no statistically significant effect on CMT in patients with RP with or without CMO. ${ }^{3}$

\section{Oral iodine}

While oral iodine has not been trialled specifically for RP-CMO, higher urinary iodine concentration has been observed to be significantly associated with reduced CMT in non-smoking adults with RP-CMO. ${ }^{92}$

\section{Surgical}

Laser

In 1987, grid laser photocoagulation was undertaken in one eye of 16 patients with bilateral RP-CMO. Six treated eyes gained one or more lines of vision, while none of the untreated eyes did. Seven untreated eyes lost one or more lines of vision, while none of the treated eyes did. Thirteen of 16 eyes showed decreased fluorescein leakage after treatment. ${ }^{93}$ Laser may remove hypoxic degenerating retina, thus reducing VEGF production. $^{94}$

\section{Vitrectomy}

In 2003, vitrectomy combined with inner limiting membrane peel was carried out on 12 eyes of 8 patients with RP-CMO refractory to treatment with acetazolamide. The presence or absence of preoperative vitreomacular traction was not confirmed. Mean CMT improved from $478 \mu \mathrm{m}$ (range, 380$570 \mu \mathrm{m}$ ) preoperatively to $260 \mu \mathrm{m}$ (range, 177-424 $\mu \mathrm{m}$ ) at 6 months. Mean VA improved from 20/115 (range, 20/60-20/ 400) preoperatively to $20 / 45$ (range, 20/30-20/100) at 6 months. $^{25}$

\section{Conclusions and future directions}

RP-CMO commonly complicates RP, however, its exact underlying pathogenesis remains uncertain. Proposed mechanisms that are most likely to be involved include breakdown of the BRB and/or RPE pump mechanism failure and/or Müller cell oedema and dysfunction. When CS are present they are most commonly located in the INL, suggesting that inner BRB dysfunction may have a greater role than the outer BRB, in development of RP-CMO. A better understanding of these mechanisms will facilitate better targeted and likely more efficacious and durable therapies.

Setting up clinical trials for RP-CMO, however, remains a challenge due to its low prevalence, the highly variable course of disease progression, significant genetic and allelic heterogeneity and very slow progression to visual loss. With the majority of studies producing levels of evidence between 3 and 4 and no large RCTs, we remain in a position where there are no studies yet providing high-level evidence for RP-CMO treatments. In the absence of RCTs, the effect of known and unknown confounders cannot be excluded. The majority of studies did not have a control group (level 4 evidence) inherently limiting the validity of findings, as these may be a result of natural history rather than the intervention. Many studies were retrospective which may be affected by recall bias. This review has highlighted the lack of high-quality evidence for RP-CMO treatments. While concrete conclusions cannot be drawn, the evidence currently available suggests that topical CAIs may be used as a first-line approach. Consideration should be given to the possibility of side effects and potential for rebound CMO. Oral CAIs may be a second-line agent, but there is the risk of more side effects.

As there are currently no treatments for the underlying retinal degeneration in RP and given the potentially reversible nature of $\mathrm{RP}-\mathrm{CMO}$, there is a real need to better understand disease mechanisms and undertake prospective clinical trials of therapeutic agents to provide the evidence base to improve treatment of RP-CMO. Successful management of CMO should aim to both improve quality and quantity of vision in the short term and slow the rate of vision loss over time.

Contributors SS: substantial contributions to the design of the work; the acquisition, analysis and interpretation of data for the work. Drafting the work. Final approval of the version to be published. Agreement to be accountable for all aspects of the work in ensuring that questions related to the accuracy or integrity of any part of the work are appropriately investigated and resolved. GL: substantial contributions to the design of the work; the acquisition, analysis and interpretation of data for the work. Revising the work critically for important intellectual content. Final approval of the version to be published. Agreement to be accountable for all aspects of the work in ensuring that questions related to the accuracy or integrity of any part of the work are appropriately investigated and resolved. MM: substantial contributions to the conception and design of the work; the acquisition, analysis and interpretation of data for the work. Revising the work critically for important intellectual content. Final approval of the version to be published. Agreement to be accountable for all aspects of the work in ensuring that questions related to the accuracy or integrity of any part of the work are appropriately investigated and resolved.

Funding This work was supported by grants from the National Institute for Health Research Biomedical Research Centre at Moorfields Eye Hospital National Health Service Foundation Trust and UCL Institute of Ophthalmology, Fight For Sight (UK), The Macular Society (UK), Moorfields Eye Hospital Special Trustees, Moorfields Eye Charity, by a multiuser equipment grant from The Wellcome Trust (099173/Z/12/Z), the Foundation Fighting Blindness (FFB; USA), Bayer UK, and Retinitis Pigmentosa Fighting Blindness. Professor Michel Michaelides is a recipient of an FFB Career Development Award.

Competing interests None declared.

Provenance and peer review Not commissioned; externally peer reviewed.

Open Access This is an Open Access article distributed in accordance with the terms of the Creative Commons Attribution (CC BY 4.0) license, which permits others to distribute, remix, adapt and build upon this work, for commercial use, provided the original work is properly cited. See: http://creativecommons.org/ licenses/by/4.0/

\section{REFERENCES}

1 Hajali M, Fishman GA, Anderson RJ. The prevalence of cystoid macular oedema in retinitis pigmentosa patients determined by optical coherence tomography. Br J Ophthalmol 2008;92:1065-8.

2 Testa F, Rossi S, Colucci R, et al. Macular abnormalities in Italian patients with retinitis pigmentosa. Br J Ophthalmol 2014;98:946-50.

3 Adackapara CA, Sunness JS, Dibernardo CW, et al. Prevalence of cystoid macular edema and stability in OCT retinal thickness in eyes with retinitis pigmentosa during a 48-week lutein trial. Retina (Philadelphia, Pa) 2008;28:103-10.

4 Ozdemir H, Karacorlu M, Karacorlu S. Intravitreal triamcinolone acetonide for treatment of cystoid macular oedema in patients with retinitis pigmentosa. Acta Ophthalmol Scand 2005;83:248-51.

5 Liew G, Michaelides M, Bunce C. A comparison of the causes of blindness certifications in England and Wales in working age adults (16-64 years), 19992000 with 2009-2010. BMJ Open 2014;4:e004015.

6 Scorolli L, Morara M, Meduri A, et al. Treatment of cystoid macular edema in retinitis pigmentosa with intravitreal triamcinolone. Arch Ophthalmol 2007; 125:759-64.

7 Kent D, Vinores SA, Campochiaro PA. Macular oedema: the role of soluble mediators. Br J Ophthalmol 2000;84:542-5.

8 Vinores SA, Derevjanik NL, Ozaki H, et al. Cellular mechanisms of blood-retinal barrier dysfunction in macular edema. Doc Ophthalmol 1999;97:217-28. 
9 Rizzolo LJ. Polarity and the development of the outer blood-retinal barrier. Histol Histopathol 1997;12:1057-67.

10 Vinores SA. The retina and its disorders. Breakdown of the blood-Retinal Barrier. Oxford: Elsevier, 2010:52.

11 Vinores SA, Kuchle M, Derevjanik NL, et al. Blood-retinal barrier breakdown in retinitis pigmentosa: light and electron microscopic immunolocalization. Histol Histopathol 1995;10:913-23.

12 Spalton DJ, Rahi AH, Bird AC. Immunological studies in retinitis pigmentosa associated with retinal vascular leakage. Br J Ophthalmol 1978;62:183-7.

13 Miyake K, Ibaraki N. Prostaglandins and cystoid macular edema. Surv Ophthalmol 2002:47(Suppl 1):S203-18.

14 Enea NA, Hollis TM, Kern JA, et al. Histamine $\mathrm{H} 1$ receptors mediate increased blood-retinal barrier permeability in experimental diabetes. Arch Ophthalmol 1989;107:270-4

15 Kuijpers RW, Baarsma S, van Hagen PM. Treatment of cystoid macular edema with octreotide. N Engl J Med 1998;338:624-6.

16 Claudio L, Martiney JA, Brosnan CF. Ultrastructural studies of the blood-retina barrier after exposure to interleukin-1 beta or tumor necrosis factor-alpha. Lab Invest 1994;70:850-61.

17 Hamann S. Molecular mechanisms of water transport in the eye. Int Rev Cytol 2002 (215):395-431.

18 Reichenbach A, Wurm A, Pannicke T, et al. Muller cells as players in retinal degeneration and edema. Graefes Arch Clin Exp Ophthalmol 2007;245:627-36.

19 Hibino $\mathrm{H}$, Inanobe $\mathrm{A}$, Furutani $\mathrm{K}$, et al. Inwardly rectifying potassium channels: their structure, function, and physiological roles. Physiol Rev 2010;90:291-366

20 Makiyama Y, Oishi A, Otani A, et al. Prevalence and spatial distribution of cystoid spaces in retinitis pigmentosa: investigation with spectral domain optical coherence tomography. Retina 2014:34:981-8.

21 Rahi AH. Autoimmunity and the retina. II. Raised serum IgM levels in retinitis pigmentosa. Br J Ophthalmol 1973;57:904-9.

22 Spiro $R$, Weleber $R$, Kimberling $W$. Serum IgM in retinitis pigmentosa: a genetic study. Clin Genet 1978;13:295-304.

23 Heckenlively JR, Aptsiauri N, Nusinowitz $S$, et al. Investigations of antiretinal antibodies in pigmentary retinopathy and other retinal degenerations. Trans Am Ophthalmol Soc 1996;94:179-200; discussion-6.

24 Chant SM, Heckenlively J, Meyers-Elliott RH. Autoimmunity in hereditary retinal degeneration. I. Basic studies. Br J Ophthalmol 1985;69:19-24.

25 Garcia-Arumi J, Martinez V, Sararols L, et al. Vitreoretinal surgery for cystoid macular edema associated with retinitis pigmentosa. Ophthalmology 2003;110:1164-9.

26 Schepens $C L$, Avila MP, Jalkh AE, et al. Role of the vitreous in cystoid macular edema. Surv Ophthalmol 1984;28(Suppl):499-504.

27 Takezawa M, Tetsuka S, Kakehashi A. Tangential vitreous traction: a possible mechanism of development of cystoid macular edema in retinitis pigmentosa. Clin Ophthalmol 2011;5:245-8.

28 Hee MR, Puliafito CA, Wong C, et al. Quantitative assessment of macular edema with optical coherence tomography. Arch Ophthalmol 1995;113: 1019-29.

29 Hirakawa $H$, lijima H, Gohdo $T$, et al. Optical coherence tomography of cystoid macular edema associated with retinitis pigmentosa. Am J Ophthalmol 1999;128:185-91.

30 Apushkin MA, Fishman GA, Janowicz MJ. Monitoring cystoid macular edema by optical coherence tomography in patients with retinitis pigmentosa. Ophthalmology 2004;111:1899-904.

31 Kim YJ, Joe SG, Lee DH, et al. Correlations between spectral-domain OCT measurements and visual acuity in cystoid macular edema associated with retinitis pigmentosa. Invest Ophthalmol Vis Sci 2013;54:1303-9.

32 Oishi A, Otani A, Sasahara M, et al. Photoreceptor integrity and visual acuity in cystoid macular oedema associated with retinitis pigmentosa. Eye (Lond) 2009;23:1411-6.

33 Aizawa S, Mitamura Y, Baba T, et al. Correlation between visual function and photoreceptor inner/outer segment junction in patients with retinitis pigmentosa. Eye (Lond) 2009:23:304-8.

34 Sandberg MA, Brockhurst RJ, Gaudio AR, et al. The association between visual acuity and central retinal thickness in retinitis pigmentosa. Invest Ophthalmol Vis SCi 2005:46:3349-54.

35 Dinc UA, Yenerel M, Tatlipinar $S$, et al. Correlation of retinal sensitivity and retinal thickness in central serous chorioretinopathy. Ophthalmologica 2010;224:2-9.

36 Okada K, Yamamoto S, Mizunoya S, et al. Correlation of retinal sensitivity measured with fundus-related microperimetry to visual acuity and retinal thickness in eyes with diabetic macular edema. Eye (Lond) 2006;20:805-9.

37 Carpineto $\mathrm{P}$, Ciancaglini M, Di Antonio L, et al. Fundus microperimetry patterns of fixation in type 2 diabetic patients with diffuse macular edema. Retina (Philadelphia, Pa) 2007;27:21-9.

38 Liew G, Moore AT, Webster AR, et al. Efficacy and prognostic factors of response to carbonic anhydrase inhibitors in management of cystoid macular edema in retinitis pigmentosa. Invest Ophthalmol Vis Sci 2015;56:1531-6.
39 Kim C, Chung H, Yu HG. Association of p.P347L in the rhodopsin gene with early-onset cystoid macular edema in patients with retinitis pigmentosa. Ophthalmic Genet 2012;33:96-9.

40 Apushkin MA, Fishman GA, Grover $\mathrm{S}$, et al. Rebound of cystoid macular edema with continued use of acetazolamide in patients with retinitis pigmentosa. Retina (Philadelphia, Pa) 2007;27:1112-8.

41 Chen JC, Fitzke FW, Bird AC. Long-term effect of acetazolamide in a patient with retinitis pigmentosa. Invest Ophthalmol Vis Sci 1990:31:1914-8.

42 Fishman GA, Apushkin MA. Continued use of dorzolamide for the treatment of cystoid macular oedema in patients with retinitis pigmentosa. Br J Ophthalmol 2007:91:743-5.

43 Fishman GA, Gilbert LD, Anderson RJ, et al. Effect of methazolamide on chronic macular edema in patients with retinitis pigmentosa. Ophthalmology 1994;101:687-93.

44 Fishman GA, Gilbert LD, Fiscella RG, et al. Acetazolamide for treatment of chronic macular edema in retinitis pigmentosa. Arch Ophthalmol 1989;107:1445-52.

45 Fishman GA, Glenn AM, Gilbert LD. Rebound of macular edema with continued use of methazolamide in patients with retinitis pigmentosa. Arch Ophthalmol 1993:111:1640-6.

46 Genead MA, Fishman GA. Efficacy of sustained topical dorzolamide therapy for cystic macular lesions in patients with retinitis pigmentosa and usher syndrome. Arch Ophthalmol 2010;128:1146-50.

47 Grover S, Apushkin MA, Fishman GA. Topical dorzolamide for the treatment of cystoid macular edema in patients with retinitis pigmentosa. Am J Ophthalmol 2006;141:850-8.

48 Grover S, Fishman GA, Fiscella RG, et al. Efficacy of dorzolamide hydrochloride in the management of chronic cystoid macular edema in patients with retinitis pigmentosa. Retina (Philadelphia, Pa) 1997:17:222-31.

49 Ikeda Y, Hisatomi T, Yoshida N, et al. The clinical efficacy of a topical dorzolamide in the management of cystoid macular edema in patients with retinitis pigmentosa. Graefes Arch Clin Exp Ophthalmol 2012;250:809-14.

50 Ikeda Y, Yoshida N, Notomi S, et al. Therapeutic effect of prolonged treatment with topical dorzolamide for cystoid macular oedema in patients with retinitis pigmentosa. Br J Ophthalmoly 2013;97:1187-91.

51 Orzalesi N, Pierrottet C, Porta A, et al. Long-term treatment of retinitis pigmentosa with acetazolamide. A pilot study. Graefes Arch Clin Exp Ophthalmol 1993;231:254-6.

52 Pacella E, Arrico L, Santamaria V, et al. Dorzolamide chlorhydrate versus acetazolamide in the management of chronic macular edema in patients with retinitis pigmentosa: description of three case reports. Ophthalmol Eye Dis. 2014:6:21-6.

53 Thobani A, Fishman GA. The use of carbonic anhydrase inhibitors in the retreatment of cystic macular lesions in retinitis pigmentosa and $\mathrm{X}$-linked retinoschisis. Retina (Philadelphia, Pa) 2011:31:312-5.

54 Goren SB, Newell FW, O'Toole JJ. The localization of diamox-S35 in the rabbit eye. Am J Ophthalmol. 1961:51:87-93.

55 Lin APO-N, S. Diseases of the head and neck. In: Bope ET, Kellerman RD, eds. Conn's current therapy 2015. Philadelphia: Elsevier Saunders, 2015:323.

56 Penfold PL, Wen L, Madigan MC, et al. Triamcinolone acetonide modulates permeability and intercellular adhesion molecule-1 (ICAM-1) expression of the ECV304 cell line: implications for macular degeneration. Clin Exp Immunol 2000;121:458-65.

57 Moshfeghi DM, Kaiser PK, Scott IU, et al. Acute endophthalmitis following intravitreal triamcinolone acetonide injection. Am J Ophthalmol 2003;136:791-6.

58 Roth DB, Chieh J, Spirn MJ, et al. Noninfectious endophthalmitis associated with intravitreal triamcinolone injection. Arch Ophthalmol 2003;121:1279-82.

59 Jonas JB, Hayler JK, Sofker A, et al. Intravitreal injection of crystalline cortisone as adjunctive treatment of proliferative diabetic retinopathy. Am J Ophthalmol 2001:131:468-71.

60 Ahn SJ, Kim KE, Woo SJ, et al. The effect of an intravitreal dexamethasone implant for cystoid macular edema in retinitis pigmentosa: a case report and literature review. Ophthalmic Surg Lasers Imaging Retina 2014;45:160-4.

61 Alhassan M, Quintyn JC. Unilateral intravitreal dexamethasone implant for bilateral retinitis pigmentosa-related macular edema. Graefes Arch Clin Exp Ophthalmol 2013:251:2827-8.

62 Barge S, Rothwell R, Sepulveda P, et al. Intravitreal and subtenon depot triamcinolone as treatment of retinitis pigmentosa associated cystoid macular edema. Case Rep Ophthalmol Med 2013;2013:591681.

63 Buchaim G, Rezende MP, Maia M. [Intravitreal implantation of Ozurdex(R) chronic delivery system for management of macular edema related to retinitis pigmentosa: case report]. Arq Bras Oftalmol 2013;76:377-9.

64 Giusti C, Forte R, Vingolo EM. Deflazacort treatment of cystoid macular edema in patients affected by retinitis pigmentosa: a pilot study. Eur Rev Med Pharmacol Sci 2002;6:1-8.

65 Kim JE. Intravitreal triamcinolone acetonide for treatment of cystoid macular edema associated with retinitis pigmentosa. Retina (Philadelphia, $\mathrm{Pa}$ ) 2006:26:1094-6. 
66 Minnella AM, Falsini B, Bamonte G, et al. Optical coherence tomography and focal electroretinogram evaluation of cystoid macular edema secondary to retinitis pigmentosa treated with intravitreal triamcinolone: case report. Eur J Ophthalmol 2006;16:883-6.

67 Patil L, Lotery AJ. Coat's-like exudation in rhodopsin retinitis pigmentosa: successful treatment with an intravitreal dexamethasone implant. Eye (Lond) 2014;28:449-51.

68 Saatci AO, Selver OB, Seymenoglu G, et al. Bilateral intravitreal dexamethasone implant for retinitis pigmentosa-related macular edema. Case Rep Ophthalmol 2013;4:53-8.

69 Sallum JM, Farah ME, Saraiva VS. Treatment of cystoid macular edema related to retinitis pigmentosa with intravitreal triamcinolone acetonide: case report. Adv Exp Med Biol 2003;533:79-81.

70 Saraiva VS, Sallum JM, Farah ME. Treatment of cystoid macular edema related to retinitis pigmentosa with intravitreal triamcinolone acetonide. Ophthalmic Surg Lasers Imaging 2003;34:398-400.

71 Schaal Y, Hondur AM, Tezel TH. Subtenon triamcinolone for cystoid macular edema due to retinitis pigmentosa unresponsive to oral acetazolamide. Can J Ophthalmol 2016;51:e113-5

72 Srour M, Querques G, Leveziel N, et al. Intravitreal dexamethasone implant (Ozurdex) for macular edema secondary to retinitis pigmentosa. Graefes Arch Clin Exp Ophthalmol 2013;251:1501-6.

73 Urban KE, Quiram PA, Trese MT. Subretinal triamcinolone acetonide associated with improvement of cystoid macular edema in a patient with retinitis pigmentosa. Retin Cases Brief Rep 2009;3:47-9.

74 Wang C, Hu J, Bernstein PS, et al. Intravitreal injection of triamcinolone acetonide for macular edema due to retinitis pigmentosa and other retinal diseases. Adv Exp Med Biol 2006;572:309-14.

75 Haller JA, Bandello F, Belfort R, Jr., et al. Randomized, sham-controlled trial of dexamethasone intravitreal implant in patients with macular edema due to retinal vein occlusion. Ophthalmology 2010;117:1134-46.e3.

76 Scott IU, Ip MS, VanVeldhuisen PC, et al. A randomized trial comparing the efficacy and safety of intravitreal triamcinolone with standard care to treat vision loss associated with macular edema secondary to branch retinal vein occlusion: the Standard Care vs Corticosteroid for Retinal Vein Occlusion (SCORE) study report 6. Arch Ophthalmol 2009;127:1115-28.

77 Park S, Lim LT, Gavin MP. Topical steroidal and nonsteroidal antiinflammatory drugs for the treatment of cystoid macular edema in retinitis pigmentosa. Retin Cases Brief Rep 2013;7:134-6.

78 Lemos Reis RF, Moreira-Goncalves N, Estrela Silva SE, et al. Comparison of topical dorzolamide and ketorolac treatment for cystoid macular edema in retinitis pigmentosa and Usher's syndrome. Ophthalmologica 2015;233:43-50.

79 Brown DM, Heier JS, Ciulla T, et al. Primary endpoint results of a phase II study of vascular endothelial growth factor trap-eye in wet age-related macular degeneration. Ophthalmology 2011;118:1089-97.
80 Salom D, Diaz-Llopis M, Garcia-Delpech S, et al. Aqueous humor levels of vascular endothelial growth factor in retinitis pigmentosa. Invest Ophthalmol Vis Sci 2008;49:3499-502.

81 Querques G, Prascina F, laculli C, et al. Intravitreal pegaptanib sodium (Macugen) for refractory cystoid macular edema in pericentral retinitis pigmentosa. Int Ophthalmol 2009;29:103-7.

82 Yuzbasioglu E, Artunay 0, Rasier R, et al. Intravitreal bevacizumab (Avastin) injection in retinitis pigmentosa. Curr Eye Res 2009:34:231-7.

83 Artunay 0 , Yuzbasioglu E, Rasier R, et al. Intravitreal ranibizumab in the treatment of cystoid macular edema associated with retinitis pigmentosa. J Ocul Pharmacol Ther 2009;25:545-50.

84 Moustafa GA, Moschos MM. Intravitreal aflibercept (Eylea) injection for cystoid macular edema secondary to retinitis pigmentosa - a first case report and short review of the literature. BMC Ophthalmol 2015;15:44.

85 Strong SA, Gurbaxani A, Michaelides M. Treatment of retinitis pigmentosa-associated cystoid macular oedema using intravitreal aflibercept (Eylea) despite minimal response to ranibizumab (Lucentis): a case report. Case Rep Ophthalmol 2016;7:389-97.

86 Shah CR, Brent MH. Treatment of retinitis pigmentosa-related cystoid macular edema with intravitreous ranibizumab. Retin Cases Brief Rep 2010;4:291-3.

87 Triolo G, Pierro L, Parodi MB, et al. Spectral domain optical coherence tomography findings in patients with retinitis pigmentosa. Ophthalmic Res 2013;50: 160-4.

88 Battaglia Parodi M, De Benedetto U, Knutsson KA, et al. Juxtafoveal choroidal neovascularization associated with retinitis pigmentosa treated with intravitreal bevacizumab. J Ocul Pharmacol Ther 2012;28:202-4.

89 Malik A, Sood S, Narang S. Successful treatment of choroidal neovascular membrane in retinitis pigmentosa with intravitreal bevacizumab. Int Ophthalmol 2010;30:425-8

90 Melo GB, Farah ME, Aggio FB. Intravitreal injection of bevacizumab for cystoid macular edema in retinitis pigmentosa. Acta Ophthalmol Scand 2007;85:461-3.

91 Aleman TS, Duncan JL, Bieber ML, et al. Macular pigment and lutein supplementation in retinitis pigmentosa and Usher syndrome. Invest Ophthalmol Vis Sci 2001;42:1873-81.

92 Sandberg MA, Pearce EN, Harper $S$, et al. The relationship of central foveal thickness to urinary iodine concentration in retinitis pigmentosa with or without cystoid macular edema. JAMA Ophthalmol 2014;132:1209-14.

93 Newsome DA, Blacharski PA. Grid photocoagulation for macular edema in patients with retinitis pigmentosa. Am J Ophthalmol 1987;103:161-6.

94 Stefansson $\mathrm{E}$. The therapeutic effects of retinal laser treatment and vitrectomy. A theory based on oxygen and vascular physiology. Acta Ophthalmol Scand 2001;79:435-40. 